\title{
Links Between Teachers' Liking of Students, Peer Inclusion, and Students' Academic Achievement: A Two-Wave Longitudinal Study
}

\author{
Stefania Sette ${ }^{1} \cdot$ Luciano Gasser $^{2} \cdot$ Jeanine Grütter ${ }^{3}$
}

Received: 21 January 2019 / Accepted: 22 May 2019 / Published online: 3 June 2019

(c) Springer Science+Business Media, LLC, part of Springer Nature 2019

\begin{abstract}
Students who are more liked by their teachers tend to be included by their peers and to perform successfully at school. Yet, very little is known whether peer inclusion can mediate the effect of teachers' liking of students on students' academic achievement. Teachers from Grades 5 and 6 reported their liking of each student and academic achievement $(N=1209 ; 49 \%$ females), whereas peers rated the inclusion of classmates. Results from a multilevel growth curve model revealed that, only at the individual level, higher values of peer inclusion mediated the association between teachers' liking of students and academic achievement over time. This study provides new insights into the complex associations between teachers' liking of students and academic achievement during early adolescence.
\end{abstract}

Keywords Teachers' liking of students $\cdot$ Peer inclusion $\cdot$ Academic achievement $\cdot$ Early adolescence

\section{Introduction}

Poor academic adjustment represents an important risk factor for children and adolescents' subsequent school dropout, mental health problems, and behavioral difficulties (McLeod et al. 2012; Miles and Stipek 2006; Schwartz et al. 2008; Wang and Fredericks 2014). In order to prevent such negative developments, researchers focused on individual and contextual factors that promote children's academic achievement (Hughes et al. 2009; Kopystynska et al. 2016; Mercer and DeRosier 2008; Zuffianò et al. 2013). Among individual factors, higher levels of academic motivation, academic self-efficacy, and prosocial behavior have been positively related to students' academic achievement (Caprara et al. 2014; Hughes et al. 2009). Regarding the contextual factors, previous researchers highlighted the role of positive social relationships with peers and teachers in

Stefania Sette

stefania.sette@uniroma1.it

1 Faculty of Medicine and Psychology, Sapienza University of Rome, Via dei Marsi 78, Rome 00185, Italy

2 Institute for School and Diversity, University of Teacher Education Lucerne, Lucerne, Switzerland

3 Jacobs Center of Productive Youth Development, University of Zurich, Zurich, Switzerland students' academic achievement (Mercer and DeRosier 2008; Pianta and Hamre 2009). Students who experience higher levels of peer inclusion tend to develop a greater sense of belonging to the classroom community and to engage more in classroom activities, thereby improving their academic skills (Juvonen et al. 2012; Tetzner et al. 2017). Similarly, students who are more liked by their teachers or who have supportive relationships with them are more likely to increase their school participation and school engagement (McCormick et al. 2013; Mercer and DeRosier 2008).

Despite the evidence for the role of social relationships with teachers and peers in students' academic achievement, most previous studies have separately analyzed the contribution of peer inclusion and teachers' liking of students (i.e., the degree to which a teacher likes a specific student in the classroom) to children's academic achievement (Hughes et al. 2009; Tetzner et al. 2017; Zhang and Sun 2011). However, social relationships with teachers and peers are embedded in the same classroom environment and are dependent on each other (Chang et al. 2007; Sameroff and Mackenzie 2003). Therefore, in order to better understand how different types of classroom social relationships contribute to students' academic adjustment, this study investigated the relations between teachers' liking of students, peer inclusion, and students' academic achievement in a sample of Swiss students followed from fifth to sixth grade. Moreover, this study also analyzed the mechanisms by which teachers' liking of students could influence their 
academic achievement over time. In particular, this study investigated whether higher values of teachers' liking of students over time were linked to better academic performance through the mediational role of peer inclusion. A better understanding of the linkages between teachers' liking of students, peer inclusion, and academic achievement would permit teachers to individuate factors that are more relevant for students' academic achievement.

\section{Teachers' Liking of Students and Peer Inclusion}

Peer inclusion represents one of the most important factors for students' social and academic adjustment (Killen and Rutland 2011; Ladd et al. 2008; Mercer and DeRosier 2008; Sette et al. 2017). Even though social skills (e.g., prosocial behavior) play a relevant role in children's peer inclusion (Coplan and Weeks 2010), developmental researchers argue that social group dynamics within classrooms should be taken into consideration in order to explain why some children are more included by their peers than others (Mikami et al. 2010). More specifically, teacher's liking of students, defined as the degree of likability that teacher expresses for a specific student of the classroom (Chang et al. 2004), has been discussed as an important factor that contributes to peer group dynamics within the classrooms and students' academic achievement (Chang et al. 2007). Students may use teachers and their reactions toward classmates (e.g., positive or negative feedback) as a source of information to form perceptions of peers, which guide children's inclusionary or exclusionary behaviors (Hamm and Hoffman 2016; Hughes et al. 2001). For instance, considering studies that used peer acceptance (a construct closely related to peer inclusion), Chang et al. (2007) found a positive correlation between teachers' liking of students and peer acceptance among 6- to-12-year-old children. Taylor (1989) reported that low teachers' liking of students was related to peer rejection in early elementary grades, also controlling for their previous experiences of peer rejection.

\section{Peer Inclusion and Student's Academic Achievement}

Researchers emphasized the role of peers in children's academic adjustment, particularly during early adolescence, a developmental period characterized by a decline of parental influences and an increase of peer influences (Ladd 2003; Rubin et al. 2009; Wentzel and Muenks 2016). Indeed, children who are more socially included by peers, defined as being part of peer group activities, display higher levels of school engagement and academic performance (Buhs et al. 2006; Gallardo et al. 2016; Hughes and Chen 2011). For example, Buhs et al. (2006) found that the rejection from the peer group predicted a decrease in classroom participation and an increase of children's school avoidance in a sample of children who were followed from kindergarten through Grade 5. Additionally, Gallardo et al. (2016) reported a significant and positive association of acceptance from the peer group with academic achievement, although this association was greater during early adolescence compared to the middle adolescence.

Different mechanisms to explain why peer inclusion positively affects academic achievement have been proposed (Wentzel and Muenks 2016). For example, students who are included by their peers might experience stronger feelings of school belonging, and thus, they might be more likely to identify with academic values, cooperating academically with the classroom teachers (Roeser et al. 1996). Moreover, peers may also provide instructional support and enhance individual students' opportunities for academic growth through participation in academic group activities. Therefore, being included during an academic activity and having the opportunity to cooperate with other classmates could reinforce children's cognitive development and academic skills (e.g., Rogoff 1998). In line with this last argument, this study did not measure children's overall peer inclusion, but more specifically, it assessed students' inclusion into both an academic social group activities as well as their role in predicting academic achievement from fifth to sixth grades.

\section{The Mediating Role of Peer Inclusion}

Overall, as described by Gest and Rodkin (2011), the classroom peer ecology plays a crucial role in a positive youth development. It has been argued that peer interactions represent the primary developmental context for the acquisition not only of social skills but also of cognitive and academic competencies. In addition to peer relationships, the quality of student-teacher interactions may play a crucial role in children's social and academic development. The model described by Gest and Rodkin (2011) assumes that much of the influence of student-teacher interactions on youth social and academic outcomes might be more indirect than direct: Teachers' quality of emotional support and degree of likability toward students, or their specific relational and network-related strategies (e.g., publicly praising isolated children), might affect students' developmental outcomes indirectly by first improving peer relationships within the classroom. In order to test these mechanisms underlying teacher influences, mediational analyses with longitudinal designs should be conducted.

However, few if any studies have analyzed these mediational processes in a unique model. This study is aimed at understanding the associations among teachers' liking of students, peer inclusion, and academic achievement from Grade 5 to 6 . Teachers' liking of students may play a role in student's inclusion into group activities (Chang et al. 2007). In turn, peer inclusion may have an influence on student's academic achievement (Buhs et al. 2006; Gallardo et al. 
2016; Véronneau et al. 2010), playing a mediational role in the relation between teachers' liking of students and academic achievement. Therefore, being liked by teachers may predict higher levels of inclusion in academic and social group activities, and this, in turn, may promote student's academic achievement at school.

\section{The Current Study}

This study examined whether those students who were more liked by their teachers over time also reported higher values of their academic achievement from fifth to sixth grades (i.e., Time $1=\mathrm{T} 1$ and Time $2=\mathrm{T} 2$, respectively) via the mediational role of peer inclusion into both academic and social group activities. Classroom social dynamics can be looked at with regard to individual experiences of a single child (i.e., individual level) or the overall organization of a classroom's peer network (i.e., the classroom level; Gest and Rodkin 2011), and given the nested structure of the data, this study also explored these mediational mechanisms at the classroom level. These aims were explored in a sample of students followed from fifth to sixth grades in Switzerland. In Switzerland, the secondary school is organized by two or three different ability levels (depending on a specific Swiss canton).

Based on students' academic achievement, the upper elementary grade teachers recommend that students should be assigned to a secondary ability level. As ability tracking has important consequences for students' future academic and occupational careers (e.g., Reichelt et al. 2019), students in the upper elementary grades are under high pressure to perform academically (Gasser et al. 2017). Consequently, students may consider that the inclusion in the peer group of low-achieving classmates may have negative implications for effective group functioning (Grütter et al. 2018).

Moreover, early adolescents increasingly refer to peers as a source for their self-definitions and self-worth and, consequently, peer influences importantly contribute to students' academic and social adaption (Chen et al. 2008; Thompson et al. 2019). Therefore, understanding the link between teachers' liking of students, peer inclusion, and academic achievement might be of particular importance during the upper elementary grades in Switzerland.

\section{Method}

\section{Participants}

The study included two waves of data collection. At the first wave (spring 2014), children were in the fifth grade $\left(M_{\text {age }}=11.54, S D=0.56\right)$, and at the second wave (spring 2015), one year later, they were in the sixth grade
$\left(M_{\text {age }}=12.58, S D=0.56\right)$. The sample consisted of 1209 children (594 girls) from 61 classrooms at wave 1 and of 1009 children (508 girls) from 54 classrooms at wave 2 . The average number of students per classroom was 19.6 at wave 1 and 20.1 at wave 2. Forty-one percent of the fifth graders and $38 \%$ of the sixth graders had a migration background. Most parents completed a post-secondary diploma (50\%), followed by obligatory school (24\%), and a bachelor's degree or higher (20\%). Most of the teachers that participated in both study waves were female $(80 \%)$ and less than half of them were between 24 and 30 years old (44\%). Their ages ranged from 20 to 60 years. On average, teachers reported 11.31 years of professional experience. Head teachers were involved in the study.

\section{Attrition Analysis}

The attrition (17\% of children) was mainly due to the unavailability of students from Grades 5 to 6 because seven teachers declined the participation at T2. The Little's test (1988) for missing completely at random (MCAR) was used to test the pattern of missingness. The test was statistically significant $\left(\chi^{2}[26]=49.89, p=.003\right)$. However, by considering the single t-test produced by the program output, peer inclusion at $\mathrm{T} 1$ significantly predicted teachers' liking of students and academic achievement missingness at T2, suggesting that at least missing at random (MAR) could be supported (Enders 2010). To account for missing data, full information maximum likelihood (FIML; Baraldi and Enders 2010; Enders 2010) was used in Mplus 8 (Muthén and Muthén 1998-2017).

\section{Procedures}

The data analyzed in this paper were part of a larger Swiss study ("Social and moral judgments of disability-based exclusion: The role of teachers and peer context"; the study has been managed by the second author) about teacher and peer group influences on students' social inclusion and exclusion. Parents were informed about the aims of the study and were asked to sign and send back a form when they refused the participation of their child in the study. Parents' letters were translated into the most common immigrant languages in Switzerland. Participation rate was very high (99\%). Data collection was completed by research assistants who received a short training and written standardized instructions from the research team. Students and teachers together completed the questionnaires, which took about $30-40 \mathrm{~min}$. The study was explained to the students, and oral assent was requested (all students provided their assent to participate in the present study; $100 \%$ consent rate). The participation of the study was voluntary, and the students had the opportunity to withdraw at any point in 
time. All students received a popular student magazine as a token for their study participation. The study was reviewed for the ethical approval by the Research Commission of the University of Teacher Education Lucerne.

\section{Measures}

\section{Teachers' liking of students}

Teachers indicated how easy they found it to like a specific child of their class on a five-point scale (from $1=$ very hard to $5=$ very easy). The measure was adapted from previous researches on teachers' liking of students and demonstrated good test-retest reliability (e.g., Chang et al. 2004; McAuliffe et al. 2009).

\section{Peer inclusion}

For the assessment of student's inclusion, a peer rating procedure was used (e.g., Cassidy and Asher 1992). Children were asked to indicate how much they would like to include each of their classmates into two types of group activities. One of the activities described an academic group context, while the other activity described a social group context. The two group contexts were introduced as follows: (1) Academic context: "Imagine, you have to solve difficult problems with your friend during math. You need an additional child to complete the group because the teacher wants you to work in groups of three. Please indicate for each of your classmates how much you would like to include this child into this group activity."(2) Social context: "Imagine, you want to go to cinema with your friend. You have one cinema ticket left and you can choose someone to come with you. Indicate for each of your classmates how much you would like to include this child into the group activity." Following these two scenarios, children were presented with a list of all their classmates. Children indicated on a four-point-scale how likely they were to include each classmate into the two group activities (ranging from $1=$ very unlikely to $4=$ very likely). The list of classmates had a fixed alphabetical order. In order to create a score that indicated a student's overall inclusion level for each scenario, all the ratings that each student received from his or her classmates were averaged. Moreover, as the peer ratings in the academic and social group contexts were highly correlated at both $\mathrm{T} 1 \quad(r=0.91$, $p<.001)$ and $\mathrm{T} 2(r=0.91, p<.001)$, an overall score was computed by averaging the two ratings. Research including peer rating procedures suggested that peer ratings represent a reliable and valid measure of children's social inclusion and, consequently, are generally used in the peer relationship research (e.g., Asher et al. 1979; Buhs and Ladd 2001; Kochel et al. 2017).

\section{Academic achievement}

Academic ${ }^{1}$ achievement was measured by three items (e.g., "Able to read grade level material and answer questions about what he/she has read;" "performs academically at grade level;" "able to solve grade level math problems;" Hughes et al. 2009). Teachers responded to these items on a scale from 1 (almost never) to 5 (almost always). Cronbach's alpha was $\alpha=.94$ at both T1 and T2.

\section{Plan of Analyses}

In the first step, descriptive and correlational analyses were performed. Then, given the nested structure of the data (students within classroom), a multilevel growth curve model was used to explore the mean-level changes over time in the variables of interest by estimating the intercept (i.e., the initial level in the construct of interest) and slope (i.e., the change over time) at both within -(students) and between- (classrooms) levels (see Muthén and Muthén 1998-2017). ${ }^{2}$ Finally, the hypothesized relations were tested (i.e., change in teachers' liking of students $\rightarrow$ change in peer inclusion $\rightarrow$ change in academic achievement) both within-(students) and between-(classrooms) levels using a multivariate multilevel growth curve model. To test the statistical significance of the mediational role of peer inclusion in the association between teachers' liking of students and academic achievement, the upper and lower values for the $95 \%$ confidence limits (CI) of the mediated effect were computed with the RMediation package (CI; Tofighi and MacKinnon 2011). All models were estimated by using the maximum likelihood estimator with robust standard errors (MLR) in Mplus 8 (Muthén and Muthén 1998-2017).

\section{Results}

\section{Descriptive Analyses}

Means and standard deviations of the study variables for each time point are reported separately for boys and girls as well as for the total sample (see Table 1). Results from a series of analyses of variance (ANOVAs) revealed significant gender differences for teachers' liking of students at

\footnotetext{
${ }^{1}$ Since these data are part of a larger research project, data on students' academic achievement at $\mathrm{T} 1$ have been used in previous articles (Gasser et al. 2017, 2018).

2 Three-level growth curve models (level-1 = time; level-2 = students; level-3 = classrooms) can be estimated in Mplus structuring the dataset in a wide format and using a two-level framework as explained in the Mplus User Guide (see example 9.12; Muthén and Muthén 1998-2017). Given the presence of only two waves of data, the residual variances of the indicators were fixed at zero to allow model identification.
} 
Table 1 Means (M) and standard deviations (SD) at the two time points for girls, boys, and total sample

\begin{tabular}{|c|c|c|c|c|c|c|}
\hline \multirow[b]{2}{*}{ Variable } & \multicolumn{2}{|l|}{ Girls } & \multicolumn{2}{|l|}{ Boys } & \multicolumn{2}{|c|}{$\begin{array}{l}\text { Total } \\
\text { sample }\end{array}$} \\
\hline & $M$ & $S D$ & $M$ & $S D$ & $M$ & $S D$ \\
\hline Teachers' Liking T1 & 4.50 & 0.71 & 4.20 & 0.85 & 4.35 & 0.80 \\
\hline Teachers' Liking T2 & 4.46 & 0.77 & 4.14 & 0.93 & 4.30 & 0.87 \\
\hline Peer inclusion T1 & 2.59 & 0.45 & 2.50 & 0.45 & 2.54 & 0.45 \\
\hline Peer inclusion $\mathrm{T} 2$ & 2.62 & 0.48 & 2.56 & 0.49 & 2.59 & 0.49 \\
\hline Academic Achievement T1 & 3.93 & 1.08 & 3.82 & 1.18 & 3.87 & 1.13 \\
\hline Academic Achievement T2 & 3.94 & 1.15 & 3.81 & 1.20 & 3.87 & 1.18 \\
\hline
\end{tabular}

Table 2 Bivariate correlations among study variables

\begin{tabular}{lllllll}
\hline Variable & 1 & 2 & 3 & 4 & 5 & 6 \\
\hline 1.Teachers' Liking T1 & - & & & & \\
2.Teachers' Liking T2 & $.57 * * *$ & - & & & \\
3.Peer inclusion T1 & $.36^{* * *}$ & $.34 * * *$ & - & & \\
4.Peer inclusion T2 & $.35^{* * *}$ & $.34 * * *$ & $.76^{* * *}$ & - & \\
5.Academic & $.32^{* * * *}$ & $.24 * * *$ & $.36^{* * *}$ & $.30^{* * *}$ & - \\
Achievement T1 & & & & & & \\
6.Academic & $.33^{* * * *}$ & $.29 * * *$ & $.39 * * *$ & $.36 * * *$ & $.89 * * *$ & - \\
Achievement T2 & & & & & & \\
\hline
\end{tabular}

T1 Time 1,T2 Time 2

$* * * p<.001$

$\mathrm{T} 1, F(1,1203)=44.563, p<.001$, partial $\eta^{2}=.04$, and at $\mathrm{T} 2, F(1,986)=34.974, p<.001$, partial $\eta^{2}=.03$. Compared to boys, girls were more liked by their teachers at $\mathrm{T} 1$ and T2. A significant gender difference for students' inclusion at $\mathrm{T} 1$ was also found, $F(1,1206)=12.161$, $p<.001$, partial $\eta^{2}=.01$. As shown in Table 1 , girls displayed higher ratings in peer inclusion than boys at T1. No significant gender differences emerged for students' academic achievement at $\mathrm{T} 1, F(1,1193)=2.953, p=.09$, partial $\eta^{2}=.01$, and $\mathrm{T} 2, F(1,985)=3.160, p=.08$, partial $\eta^{2}=.01$, and for peer inclusion at $\mathrm{T} 2, F(1,1031)=3.484$, $p=.06$, partial $\eta^{2}=.01$.

Correlations among the study variables are reported in Table 2. Results revealed significant and positive associations between teachers' liking of students at T1 and teachers' liking of students at T2; peer inclusion at T1 and peer inclusion at T2; and academic achievement at T1 and academic achievement at T2. Teachers' liking of students at T1 and teachers' liking of students at T2 were also positively related to peer inclusion (both at T1 and T2) and children's academic achievement (at $\mathrm{T} 1$ and $\mathrm{T} 2$ ). Moreover, peer inclusion at $\mathrm{T} 1$ and $\mathrm{T} 2$ positively correlated with academic achievement at $\mathrm{T} 1$ and $\mathrm{T} 2$.
Multilevel Growth Curve Model of Teachers' Liking of Students: Unconditional Model

Before running the multilevel growth curve model, the Intraclass Correlation Coefficient (ICC) was computed to ascertain the amount of variability at the classroom level. The ICCs were 0.16 and 0.18 for teachers' liking of students at $\mathrm{T} 1$ and T2, respectively. Although the multilevel growth curve model showed a lack of significant mean-level change for teachers' liking of students (mean slope $=-.056, \mathrm{SE}=.048, p=.238$ ), there were significant variabilities around this average effect at both individual $\left(\mathrm{s}^{2}=.506, \mathrm{SE}=.037, p=.001\right)$ and classroom- $\left(\mathrm{s}^{2}=.094, \mathrm{SE}=.028, p=.001\right)$ levels, thereby indicating meaningful inter-individual and inter-classroom differences in teachers' liking of students over time. Interestingly, there were also significant inter-individual $\left(\mathrm{s}^{2}=.531\right.$, $\mathrm{SE}=.046, p=.001)$ and inter-classroom variabilities $\left(\mathrm{s}^{2}\right.$ $=.104, \mathrm{SE}=.020, p=.001)$ in teachers' liking of students at $\mathrm{T} 1$ (mean intercept $=4.343, \mathrm{SE}=.046, p=.001)^{3}$.

\section{Multilevel Growth Curve Model of Peer Inclusion: Unconditional Model}

The ICCs were 0.10 and 0.07 for peer inclusion at T1 and $\mathrm{T} 2$, respectively. The multilevel growth curve model showed a significant mean-level change for peer inclusion (mean slope $=.039, \mathrm{SE}=.020, p=.049)$, revealing a slight increase of peer inclusion from $\mathrm{T} 1$ to $\mathrm{T} 2$. In addition, significant variabilities around this average effect were found at both individual $\left(\mathrm{s}^{2}=.087, \mathrm{SE}=.008, p=.001\right)$ and classroom-levels $\left(\mathrm{s}^{2}=.018, \mathrm{SE}=.006, p=.002\right)$, and these variabilities indicated meaningful inter-individual and interclassroom differences in peer inclusion over time. Interestingly, there were significant inter-individual $\left(\mathrm{s}^{2}=.184\right.$, $\mathrm{SE}=.010, p=.001)$ and inter-classroom variabilities $\left(\mathrm{s}^{2}=.020, \mathrm{SE}=.006, p=.001\right)$ in peer inclusion at $\mathrm{T} 1$ (mean intercept $=2.546, \mathrm{SE}=.022, p=.001$ ).

\section{Multilevel Growth Curve Model of Academic Achievement: Unconditional Model}

The ICCs were 0.10 and 0.09 for academic achievement at $\mathrm{T} 1$ and T2, respectively. Although the multilevel growth curve model showed a lack of significant mean-level change for academic achievement (mean slope $=-.014$, SE $=.033, p=.672)$, significant variabilities around this average effect were found at both individual $\left(\mathrm{s}^{2}=.252\right.$, $\mathrm{SE}=.017, p=.001)$ and classroom levels $\left(\mathrm{s}^{2}=.046, \mathrm{SE}\right.$

\footnotetext{
${ }_{3}^{3}$ Since all possible parameters were estimated in multilevel growth curves (i.e., zero degrees of freedom), no fit indexes are reported because the models were just identified (i.e., perfect fit to the data; see Kline, 2015).
} 
$=.013, p=.001)$, thereby indicating meaningful interindividual and inter-classroom differences in academic achievement over time. Interestingly, significant interindividual $\left(\mathrm{s}^{2}=1.160, \mathrm{SE}=.062, p=.001\right)$ and interclassroom variabilities $\left(\mathrm{s}^{2}=.125, \mathrm{SE}=.030, p=.001\right)$ were found in academic achievement at $\mathrm{T} 1$ (mean intercept $=3.864, \mathrm{SE}=.055, p=.001$ ).

\section{Multilevel Growth Curve Model of Teachers' Liking of Students, Peer Inclusion, and Academic Achievement: Full Model}

To test the mediational model ${ }^{4}$, a multivariate (or parallel) multilevel growth curve model was run by examining the hypothesized paths at both the individual and classroom levels. To control for initial differences in the constructs of interest, the slopes were regressed on the intercepts. As shown in Table 3, the slope of teachers' liking of students was positively associated with the slope of peer inclusion, which in turn was linked to higher academic achievement at the individual level, but not at the classroom level. Furthermore, the slope of teachers' liking of students was also positively related to the slope of academic achievement at the individual level. Importantly, the changes in peer inclusion played a mediational role in the association between the changes in teachers' liking of students and the changes in academic achievement at the individual level (b $=0.014, \mathrm{SE}=0.006 ; 95 \% \mathrm{CI}=0.003,0.028)$. The changes in peer inclusion did not play a mediational role in the association between the changes in teachers' liking of students and changes in academic achievement at the classroom-level $(\mathrm{b}=0.002, \mathrm{SE}=0.032 ; 95 \% \mathrm{CI}=-0.066$, $0.075)^{5}$.

\footnotetext{
$\overline{4}$ An alternative multivariate multilevel growth curve model was run in order to analyze if the change in teachers' liking of students played a mediational role in the link between the change in peer inclusion and the change in academic achievement at both within-(students) and between- (classrooms) levels. Only at individual level, the changes in teachers' liking of students played a mediational role $(95 \% \mathrm{CI}=$ $0.003,0.025)$.

5 The hypothesized mediational model was tested among boys and girls and Swiss and non-Swiss students. Results from models run separately for boys and girls revealed that, at the student-level, the changes in peer inclusion were a significant mediator of the link between changes in teachers' liking of students and changes in academic achievement only for boys $(95 \% \mathrm{CI}=0.002,0.038)$ but not for girls $(95 \% \mathrm{CI}=-0.003,0.031)$. Also, results indicated that, at the student level, the changes in peer inclusion were a significant mediator of the link between changes in teachers' liking of students and changes in academic achievement only for Swiss students $(95 \% \mathrm{CI}=0.003$, 0.028 ) but not for non-Swiss students $(95 \% \mathrm{CI}=-0.008,0.017)$. At the classroom-level, the change in peer inclusion did not play a mediational role across all groups.
}

\section{Discussion}

Researchers have argued that it is important to study the factors that lead to success in academic achievement during childhood and adolescence because students' academic difficulties represent a risk factor for health and behavioral problems later (McLeod et al. 2012; Zuffianò et al. 2013). Among these factors, experiencing emotionally supportive and secure classroom environments may represent an important condition for students' cognitive and social exploration in the classroom (Gasser et al. 2018; Pianta 1999). Moreover, if students feel liked by the teacher, they are more likely to identify with academic values of school context and cooperate with the teacher. They may also display higher academic participation and exposure to highquality teacher feedback (Wentzel and Muenks 2016). However, teacher's liking of a specific student might also enhance student's opportunities for relevant emotional and academic interactions with peers. In addition to teachers, peers have been assigned a prominent role in developmental theories about students' cognitive development (Galvan et al. 2011). Despite this, peer inclusion has been rarely considered as a meditator of the relationship between teachers' liking of students and children's academic achievement (Gest and Rodkin 2011). In the current study, one of the contributions was to consider in a unique model the role of teachers' liking of students and peer inclusion on students' academic achievement at both within-(students) and between-(classrooms) levels in a multivariate multilevel growth curve model.

Consistent with the hypotheses, a direct effect of teachers' liking of students on students' peer inclusion at the individual level was found. In other words, those students who reported higher values for teacher's liking over time also reported higher values of peer inclusion from $\mathrm{T} 1$ to $\mathrm{T} 2$. This result could suggest that students' decisions to include or exclude another peer may depend on teacher's reactions toward students and their relationships with each other (Hughes et al. 2001). For example, Chang et al. (2007), in a sample of students from 6 to 12 years, revealed that teachers' liking for their students was a significant predictor for students' liking from classmates. Similarly, Hughes et al. (2014) showed that peer nominations of student-teacher relationships in Grade 4 was related to students' peer acceptance, also controlling for students' peer acceptance the prior year.

At the individual level, a direct effect of the early peer inclusion on students' academic achievement one year later was found. More specifically, students who reported higher values in peer inclusion over time also showed higher values of academic achievement from $\mathrm{T} 1$ to $\mathrm{T} 2$. Thus, the inclusion/exclusion in an academic activity and in a social activity may be, in turn, a significant predictor of later 
Table 3 Multivariate multilevel growth curve model

\begin{tabular}{|c|c|c|c|c|c|c|}
\hline & \multicolumn{3}{|l|}{ Individual-level } & \multicolumn{3}{|l|}{ Classroom-level } \\
\hline & b (SE) & $\beta$ & $p$-value & b (SE) & $\beta$ & $p$-value \\
\hline $\mathrm{S}$ (Teachers' Liking) $\rightarrow \mathrm{S}$ (Peer Inclusion) & $0.052(0.017)$ & 0.126 & 0.002 & $-0.042(0.059)$ & -0.095 & 0.474 \\
\hline$S$ (Peer Inclusion) $\rightarrow S$ (Academic Achievement) & $0.263(0.084)$ & 0.154 & 0.002 & $-0.049(0.445)$ & -0.031 & 0.912 \\
\hline $\mathrm{S}$ (Teachers' Liking) $\rightarrow \mathrm{S}$ (Academic Achievement) & $0.080(0.024)$ & 0.114 & 0.001 & $0.128(0.180)$ & 0.183 & 0.476 \\
\hline I (Teachers' Liking) $\rightarrow$ S (Teachers' Liking) & $-0.457(0.044)$ & -0.468 & 0.000 & $-0.372(0.182)$ & -0.391 & 0.041 \\
\hline I (Teachers' Liking) $\rightarrow \mathrm{S}$ (Peer Inclusion) & $0.065(0.016)$ & 0.161 & 0.000 & $0.154(0.083)$ & 0.367 & 0.064 \\
\hline I (Teachers' Liking) $\rightarrow \mathrm{S}$ (Academic Achievement) & $0.070(0.025)$ & 0.101 & 0.005 & $0.139(0.180)$ & 0.210 & 0.438 \\
\hline I (Peer Inclusion) $\rightarrow \mathrm{S}$ (Teachers' Liking) & $0.300(0.056)$ & 0.181 & 0.000 & $0.648(0.334)$ & 0.302 & 0.053 \\
\hline I (Peer Inclusion) $\rightarrow \mathrm{S}$ (Peer Inclusion) & $-0.198(0.025)$ & -0.289 & 0.000 & $-0.491(0.126)$ & -0.518 & 0.000 \\
\hline I (Peer Inclusion) $\rightarrow$ S (Academic Achievement) & $0.214(0.045)$ & 0.183 & 0.000 & $0.181(0.378)$ & 0.121 & 0.631 \\
\hline I (Academic Achievement) $\rightarrow S$ (Teachers' Liking) & $0.004(0.022)$ & 0.006 & 0.855 & $0.107(0.174)$ & 0.124 & 0.539 \\
\hline I (Academic Achievement) $\rightarrow S$ (Peer Inclusion) & $0.023(0.010)$ & 0.084 & 0.018 & $-0.192(0.071)$ & -0.507 & 0.007 \\
\hline I (Academic Achievement) $\rightarrow S$ (Academic Achievement) & $-0.104(0.022)$ & -0.222 & 0.000 & $-0.234(0.174)$ & -0.389 & 0.179 \\
\hline \multicolumn{2}{|r|}{$\operatorname{cov}(\mathrm{SE})$} & Corr & $p$-value & $\operatorname{cov}(\mathrm{SE})$ & corr & $p$-value \\
\hline I (Teachers' Liking) $\leftrightarrow$ I (Peer Inclusion) & $0.128(0.015)$ & 0.409 & 0.000 & $0.002(0.007)$ & 0.051 & 0.742 \\
\hline I (Teachers’ Liking) $\leftrightarrow$ I (Academic Achievement) & $0.234(0.034)$ & 0.298 & 0.000 & $0.054(0.019)$ & 0.467 & 0.005 \\
\hline I (Peer Inclusion) $\leftrightarrow \mathrm{I}$ (Academic Achievement) & $0.186(0.014)$ & 0.403 & 0.000 & $0.002(0.011)$ & 0.035 & 0.868 \\
\hline
\end{tabular}

$I$ intercept, $S$ slope, $S E$ standard error, cov covariance, corr correlation

academic adjustment/maladjustment. For instance, Buhs et al. found a negative link between children's exclusion by peers and their academic achievement, highlighting that excluded children in kindergarten were more likely to perform poorly on a test of student achievement in the fifth grade (Buhs et al. 2006, 2010). This study contributed to the research by considering students' inclusion in and out of the school contexts and its role on their academic achievement. Peers may contribute to student's cognitive development (and academic achievement) by providing an interactional context that stimulates student's perspective-taking and reasoning skills (Galvan et al. 2011). Compared to adults, peers may be more likely to engage in meaningful academic discussions and to provide explanations and new points of view that are accessible to their classmates. Thus, students who are included by peers might have more opportunities for relevant cognitive interactions with peers than those who experience exclusion by their peers.

Consistent with the hypotheses and the model of Gest and Rodkin (2011), results revealed that students' peer inclusion mediated the relation between teachers' liking of students and academic achievement from Grade 5 to 6 at the individual level. In other words, higher values of teachers' liking of students over time were related to higher values of peer inclusion that in turn were associated with higher values of academic achievement from $\mathrm{T} 1$ to $\mathrm{T} 2$. Thus, the more students are liked by teachers, the more they tend to display higher levels of academic achievement over time if they are also included by peers into an academic group activity and in a social activity. Therefore, findings suggest that the teachers' liking of students may influence student's academic achievement through peer inclusion. Thus, findings shed further light on the complex social dynamics in the classroom that underlay students' academic success.

Interestingly, the mediational role of peer inclusion in the link between teachers' liking of students and academic achievement was not found at the classroom level. It is possible that the mediational role of peer inclusion has been only found at the individual level because the measures used in this study (i.e., teachers' liking of students, peer inclusion, and academic achievement) mostly captured individual aspects of students (e.g., each student has a unique relationship with his/her teacher) rather than contextual aspects such as classroom climate characterized by teacher's overall level of warmth and support and students' perceptions of classroom norms.

The present study has several strengths. First, it was a longitudinal study conducted considering a large sample of Swiss students in early adolescence. To date, only little research directly analyzed the mechanisms by which student-teacher relationships affect students' academic achievement. An additional strength of the study is that a multimethod and multi-informant approach (including 
teacher reports as well as a peer rating procedure) was used, allowing the generalizability of results across informants.

Despite these strengths, this study has several limitations. First, this study considered only two time points. Therefore, future works should consider a longer period to understand the role of peer inclusion in the link between teachers' liking of students and academic achievement over time. Second, the results of the alternative model with teachers' liking of students as a mediator in the link between peer inclusion and academic achievement was also significant, thereby suggesting more complex mediational effects that need to be further investigated in more long-term longitudinal studies. In addition, achievement tests would represent a more objective measure of students' academic achievement than teacher ratings used in the current study. Also, teachers' liking of students might be more important for students at risk (e.g., low self-efficacy beliefs, low executive functions, low socioeconomic background, socially withdrawn students) compared to students without risks (e.g., Gazelle 2006; Hamre and Pianta 2006). In other words, it is possible that teachers' liking of students differentially relate to students' peer relationships and academic outcomes in various student groups. Thus, it is important that future researches investigate relations between individual risk factors and students' relationships with teachers and peers in predicting their academic and social outcomes. Finally, it is also possible that the peer inclusion during a school activity may reinforce students' sense of security and belonging to the school context and, thus, improve their academic skills. On the contrary, being excluded by peers at school may affect students' overall wellbeing and academic achievement, reducing their feelings of security within the peer group as well as their school engagement. Therefore, future studies should also investigate students' feelings of security and belonging to the school context and their role in the link between peer inclusion and academic achievement.

\section{Conclusion}

Despite the relevant role of social relationships with teachers and peers in students' academic achievement, most previous studies have separately investigated the contribution of peer inclusion and teachers' liking of students to children's academic achievement. In the current study, the role of peer inclusion in the link between teachers' liking of students and academic achievement was considered simultaneously at both within-(students) and between-(classrooms) levels using a multivariate multilevel growth curve model in a sample of Swiss students followed from fifth to sixth grade. The results revealed that higher values of peer inclusion mediated the association between teachers' liking of students and academic achievement over time only at the individual level. Intervention programs would benefit from helping teachers to be aware that they may represent an important authority in affecting students' decisions to include or exclude classmates from academic group activities. Furthermore, intervention programs conducted in early adolescence should also work to improve students' peer inclusion in and out of the school context in order to favor their better academic achievement and overall wellbeing at school.

Acknowledgements The authors thank Dr. Antonio Zuffianò for the help and support in the analyses. The authors also thank the children and teachers who participated in this study.

Authors' Contributions SS participated in the design, performed the statistical analysis, participated in the interpretation of the data, drafted the manuscript, and revised it critically for important intellectual content; LG conceived of the study, participated in its design and coordination, acquired data, participated in the interpretation of the data, drafted the manuscript, and revised it critically for important intellectual content; and JG participated in the design and coordination of the study, acquired the data, participated in the interpretation of the data, helped to draft the manuscript, and revised it critically for important intellectual content. All authors read and approved the final manuscript.

Funding This study was funded by the Swiss National Science Foundation (13DPD3_124764).

Data Sharing Declaration The datasets generated and/or analyzed during the current study are not publicly available but are available from the corresponding author on reasonable request.

\section{Compliance with Ethical Standards}

Conflict of Interest The authors declare that they have no conflict of interest.

Ethical Approval The surveys have all received ethical clearance from the research commission of the University of Teacher Education Lucerne (Toepferstrasse 10, 6004 Lucerne, Switzerland).

Informed Consent Informed consent was obtained from all individual participants included in the study.

Publisher's note: Springer Nature remains neutral with regard to jurisdictional claims in published maps and institutional affiliations.

\section{References}

Asher, S. R., Singleton, L. C., Tinsley, B. R., \& Hymel, S. (1979). A reliable sociometric measure for preschool children. Developmental Psychology, 15, 443-444. https://doi.org/10.1037/00121649.15.4.443.

Baraldi, A. N., \& Enders, C. K. (2010). An introduction to modern missing data analyses. Journal of School Psychology, 48, 5-37. https://doi.org/10.1016/j.jsp.2009.10.001.

Buhs, E. S., \& Ladd, G. W. (2001). Peer rejection as antecedent of young children's school adjustment: an examination of mediating 
processes. Developmental Psychology, 37, 550-560. https://doi. org/10.1037/0012-1649.37.4.550.

Buhs, E. S., Ladd, G., \& Herald, S. (2006). Peer exclusion and victimization: processes that mediate the relation between peer group rejection and children's classroom engagement and achievement. Journal of Educational Psychology, 98, 1-13. https://doi.org/10. 1037/0022-0663.98.1.1.

Buhs, E. S., Ladd, G. W., \& Herald-Brown, S. L. (2010). Victimization and exclusion: Links to peer rejection, classroom engagement, and achievement. In S. R. Jimerson, S. M. Swearer \& D. L. Espelage (Eds), The handbook of school bullying: An international perspective (pp. 163-172). New York, NY: Routledge.

Caprara, G. V., Luengo Kanacri, B. P., Gerbino, M., Zuffianò, A., Alessandri, G., Vecchio, G., \& Bridgall, B. (2014). Positive effects of promoting prosocial behavior in early adolescence: evidence from a school-based intervention. International Journal of Behavioral Development, 38, 386-396. https://doi.org/10. 1177/0165025414531464.

Cassidy, J., \& Asher, S. R. (1992). Loneliness and peer relations in young children. Child Development, 63(2), 350-365. https://doi. org/10.2307/1131484.

Chang, L., Liu, H., Wen, Z., Fung, K. Y., Wang, Y., \& Xu, Y. (2004). Mediating teacher liking and moderating authoritative teaching on Chinese adolescents' perceptions of antisocial and prosocial behaviors. Journal of Educational Psychology, 96, 369-380. https://doi.org/10.1037/0022-0663.96.2.369.

Chang, L., Liu, H., Fung, K. Y., Wang, Y., Wen, Z., Li, H., \& Farver, J. M. (2007). The mediating and moderating effects of teacher preference on the relations between students' social behaviors and peer acceptance. Merrill-Palmer Quarterly, 53, 603-630.

Chen, X., Chang, L., Liu, H., \& He, Y. (2008). Effects of the peer group on the development of social functioning and academic achievement: a longitudinal study in Chinese children. Child Development, 79, 235-251.

Coplan, R. J., \& Weeks, M. (2010). Unsociability in childhood. In K. H. Rubin \& R. J. Coplan (Eds.), The development of shyness and social withdrawal (pp. 64-83). New York, NY: Guilford.

Enders, C. K. (2010). Applied missing data analysis. New York, NY: The Guilford Press.

IGallardo, L., Barrasa, A., \& Guevara-Viejo, F. (2016). Positive peer relationships and academic achievement across early and midadolescence. Social Behavior and Personality: An International Journal, 44, 1637-1648. https://doi.org/10.2224/sbp.2016.44.10. 1637

Galvan, A., Spatzier, A., \& Juvonen, J. (2011). Perceived norms and social values to capture school culture in elementary and middle school. Journal of Applied Developmental Psychology, 32, 346-353. https://doi.org/10.1016/j.appdev.2011.08.005.

Gasser, L., Grütter, J., Buholzer, A., \& Wettstein, A. (2018). Emotionally supportive classroom interactions and students' perceptions of theirteachers as caring and just. Learning and Instruction, 54, 82-92.

Gasser, L., Grütter, J., Torchetti, L., \& Buholzer, A. (2017). Competitive classroom norms and exclusion of children with academic and behaviordifficulties. Journal of Applied Developmental Psychology, 49, 1-11.

Gazelle, H. (2006). Class climate moderates peer relations and emotional adjustment in children with an early history of anxious solitude: a child environment model. Developmental Psychology, 42, 1179-1192. https://doi.org/10.1037/0012-1649.42.6.1179.

Gest, S. D., \& Rodkin, P. C. (2011). Teaching practices and elementary classroom peer ecologies. Journal of Applied Developmental Psychology, 32, 288-296. https://doi.org/10.1016/j. appdev.2011.02.004.
Grütter, J., Gasser, L., Zuffianò, A., \& Meyer, B. (2018). Promoting inclusion via cross-group friendship: the mediating role of change in trustand sympathy. Child Development 89, e414-e430.

Hamm, V., \& Hoffman, A. S. (2016). Teachers “ influence on students peer relationships and peer ecologies. In K. Wentzel \& G. Ramani (Eds.), Handbook of social influences in school contexts: Social-emotional, motivation and cognitive outcomes (pp. 208-229). New York, NY: Routledge.

Hamre, B. K., \& Pianta, R. C. (2006). Student-teacher relationships. In G. C. Bear \& K. M. Minke (Eds.), Children's needs III: Development, prevention, and intervention (pp. 59-71). Washington, DC: National Association of School Psychologists.

Hughes, J. N., \& Chen, Q. (2011). Reciprocal effects of studentteacher and student-peer relatedness: effects on academic selfefficacy. Journal of Applied Developmental Psychology, 32(5), 278-287. https://doi.org/10.1016/j.appdev.2010.03.005.

Hughes, J. N., Cavell, T. A., \& Willson, V. (2001). Further support for the developmental significance of the quality of the teacher-student relationship. Journal of School Psychology, 39, 289-301. https://doi.org/10.1016/S0022-4405(01)00074-7.

Hughes, J. N., Dyer, N., Luo, W., \& Kwok, O. (2009). Effects of peer academic reputation on achievement in academically at-risk elementary students. Journal of Applied Developmental Psychology, 30, 182-194. https://doi.org/10.1016/j.appdev.2008.12.008.

Hughes, J. N., Im, M., \& Wehrly, S. E. (2014). Effect of peer nominations of teacher-student support at individual and classroom levels on social and academic outcomes. Journal of School Psychology, 52, 309-322. https://doi.org/10.1016/j.jsp.2013.12.004.

Juvonen, J., Espinoza, G., \& Knifsend, C. (2012). The role of peer relationships in student academic and extracurricular engagement. In S. L. Christenson, A. L. Reschly \& C. Wylie (Eds.), Handbook of research on student engagement (pp. 387-401). New York, NY, US: Springer Science+Business Media. https://doi.org/10. 1007/978-1-4614-2018-7_18.

Killen, M., \& Rutland, A. (2011). Children and social exclusion: Morality, prejudice and group identity. Oxford: Wiley-Blackwell.

Kline, R. B. (2015). Principles and practice of structural equation modeling. New York, NY: Guilford Press.

Kochel, K. P., Bagwell, C. L., Ladd, G. W., \& Rudolph, K. D. (2017). Do positive peer relations mitigate transactions between depressive symptoms and peer victimization in adolescence? Journal of Applied Developmental Psychology, 51, 44-54. https://doi.org/ 10.1016/j.appdev.2017.04.003.

Kopystynska, O., Spinrad, T. L., Seay, D. M., \& Eisenberg, N. (2016). The interplay of maternal sensitivity and gentle control when predicting children's subsequent academic functioning: evidence of mediation by effortful control. Developmental Psychology, 52, 909-921. https://doi.org/10.1037/dev0000122.

Ladd, G. W. (2003). Probing the adaptive significance of children's behavior and relationships in the school context: a child by environment perspective. In R. Kail (Ed.), Advances in child development and behavior (pp. 43-104). New York, NY: Wiley.

Ladd, G. W., Herald-Brown, S. L., \& Reiser, M. (2008). Does chronic classroom peer rejection predict the development of children's classroom participation during the grade school years? Child Development, 79, 1001-1015. https://doi.org/10.1111/j.14678624.2008.01172.x.

Little, R. J. A. (1988). A test of missing completely at random for multivariate data with missing values. Journal of the American Statistical Association, 83, 1198-1202. https://doi.org/10.1080/ 01621459.1988.10478722.

McAuliffe, M. D., Hubbard, J. A., \& Romano, L. J. (2009). The role of teacher cognition and behavior in children's peer relations. Journal of Abnormal Child Psychology, 37, 665-677. https://doi. org/10.1007/s10802-009-9305-5. 
McCormick, M., O’Connor, E. E., Cappella, E., \& McClowry, S. (2013). Teacher-child relationships and academic achievement: a multi-level propensity score model approach. Journal of School Psychology, 51, 611-624. https://doi.org/10.1016/j.jsp. 2013.05.001.

McLeod, J. D., Uemura, R., \& Rohrman, S. (2012). Adolescent mental health, behavior problems, and academic achievement. Journal of Health and Social Behavior, 53, 482-497. https://doi.org/10. 1177/0022146512462888.

Mercer, S. H., \& DeRosier, M. E. (2008). Teacher preference, peer rejection, and student aggression: a prospective study of transactional influence and independent contributions to emotional adjustment and grades. Journal of School Psychology, 46, 661-685. https://doi.org/10.1016/j.jsp.2008.06.006.

Mikami, A. Y., Lerner, M. D., \& Lun, J. (2010). Social context influences on children's rejection by their peers. Child Development Perspectives, 4, 123-130. https://doi.org/10.1111/j.17508606.2010.00130.x.

Miles, S. B., \& Stipek, D. (2006). Contemporaneous and longitudinal associations between social behavior and literacy achievement in a sample of low-income elementary school children. Child Development, 77, 103-117. https://doi.org/10.1111/j.1467-8624. 2006.00859.x.

Muthén, L. K., \& Muthén, B. O. (1998-2017). Mplus user's guide. 8th Edn Los Angeles, CA: Muthén \& Muthén.

Pianta, R. C. (1999). Enhancing relationships between children and teachers. Washington, DC, US: American Psychological Association.

Pianta, R. C., \& Hamre, B. K. (2009). Conceptualization, measurement, and improvement of classroom processes: standardized observation can leverage capacity. Educational Researcher, 38 (2), 109-119. https://doi.org/10.3102/0013189X09332374.

Reichelt, M., Collischon, M., \& Eberl, A. (2019). School tracking and its role in social reproduction: reinforcing educational inheritance and the direct effects of social origin. The British Journal of Sociology. https://doi.org/10.1111/1468-4446.12655. Advanced online publication.

Roeser, R. W., Midgley, C., \& Urdan, T. C. (1996). Perception of the school environment and early adolescents' psychological and behavioral functioning in school: the mediating role of goals and belonging. Journal of Educational Psychology, 88, 408-422. https://doi.org/10.1037/0022-0663.88.3.408.

Rogoff, B. (1998). Cognition as a collaborative process. In D. Kuhn \& R. S. Siegler (Eds.), Cognition, perception, and language (Vol. 2, pp. 679-744). In W. Damon (Ed.), Handbook of child psychology (5th ed.). New York: Wiley.

Rubin, K. H., Bukowski, W. M., \& Laursen, B. (2009). Handbook of Peer Interactions, Relationships, and Groups. New York, NY: Guilfort.

Sameroff, A. J., \& Mackenzie, M. J. (2003). Research strategies for capturing transactional models of development: the limits of the possible. Development and Psychopathology, 15, 613-640. https://doi.org/10.1017/S0954579403000312.

Schwartz, D., Gorman, A. H., Duong, M. T., \& Nakamoto, J. (2008). Peer relationships and academic achievement as interacting predictors of depressive symptoms during middle childhood. Journal of Abnormal Psychology, 117, 289-299. https://doi.org/10.1037/ 0021-843X.117.2.289.

Sette, S., Spinrad, T. L., \& Baumgartner, E. (2017). The relations of preschool children's emotion knowledge and socially appropriate behaviors to peer likability. International Journal of Behavioral Development, 41, 532-541.
Taylor, A. R. (1989). Predictors of peer rejection in early elementary grades: roles of problem behavior, academic achievement, and teacher preference. Journal of Clinical Child Psychology, 18, 360-365.

Tetzner, J., Becker, M., \& Maaz, K. (2017). Development in multiple areas of life in adolescence: Interrelations between academic achievement, perceived peer acceptance, and selfesteem. International Journal of Behavioral Development, 41, 704-713. https://doi.org/10.1177/0165025416664432.

Thompson, E. L., Mehari, K. R., \& Farrell, A. D. (2019). Deviant peer factors during early adolescence: cause or consequence of physical aggression? Child Development. Advanced online publication. https://doi.org/10.1111/cdev.13242.

Tofighi, D., \& MacKinnon, D. P. (2011). RMediation: an R package for mediation analysis confidence intervals. Behavior Research Methods, 43, 692-700. https://doi.org/10.3758/ s13428-011-0076-x.

Véronneau, M. H., Vitaro, F., Brendgen, M., Dishion, T. J., \& Tremblay, R. E. (2010). Transactional analysis of the reciprocal links between peer experiences and academic achievement from middle childhood to early adolescence. Developmental Psychology, 46, 773-790. https://doi.org/10.1037/a0019816.

Wang, M. T., \& Fredericks, J. A. (2014). The reciprocal links between school engagement, youth problem behaviors, and school dropout during adolescence. Child Development, 85, 722-737. https://doi. org/10.1111/cdev.12138.

Wentzel, K. R., \& Muenks, K. (2016). Peer influence on students motivation, academic achievement, and social behavior. In K. Wentzel \& G. Ramani (Eds.), Handbook of social influences in school contexts: Social-emotional, motivation and cognitive outcomes (pp. 13-30). New York, NY: Routledge.

Zhang, X., \& Sun, J. (2011). The reciprocal relations between teachers' perceptions of children's behavior problems and teacher-child relationships in the first preschool year. Journal of Genetic Psychology, 172, 176-198. https://doi.org/10.1080/ 00221325.2010 .528077$.

Zuffianò, A., Alessandri, G., Gerbino, M., Luengo Kanacri, B. P., Di Giunta, L., Milioni, M., \& Caprara, G. V. (2013). Academic achievement: The unique contribution of self-efficacy beliefs in self-regulated learning beyond intelligence, personality traits, and self-esteem. Learning and Individual Differences, 23, 158-162. https://doi.org/10.1016/j.lindif.2012.07.010.

Stefania Sette is a resercher at the Faculty of Medicine and Psychology, Sapienza University of Rome, Italy. Her research interests focus on the role of teacher-student relationship quality on peer relationships and social behaviors in the children and adolescents.

Luciano Gasser is a professor at the Institute for School and Diversity, University of Teacher Education Lucerne, Switzerland. His research interests focus on social and moral development, moral education, classroom observation and teaching quality, and inclusive education in childhood and adolescence.

Jeanine Grütter is a post-doctoral research fellow at the Jacobs Center of Productive Youth Development, University of Zurich. Her research interests focus on the development of social categories, stereotypes and prejudice and their correlation with social-emotional and moral development in childhood and adolescence. 